\title{
O estranho e a crítica ao patriarcado: resga- tando o romance $A$ rainha do Ignoto de Emília Freitas
}

\author{
Anselmo Peres Alós
}

RÉSUMÉ: Ce travail analyse la façon dont les conventions narratives du roman gothique en Europe au XVIII siècle sont déplacées et " traduites » dans le roman brésilien à la fin du XIX siècle, en articulant des idéologèmes politiques et des structures narratives typiques du récit fantastique. L'intrigue autant que l'énonciation de style fantastique et gothique sont utilisés par Emília Freitas dans son roman A Rainha do Ignoto, paru pour la première fois en 1899. Freitas manie ces éléments formels du récit visant à resignifier les conventions gothiques et le rôle de la femme au sein de la société patriarcale brésilienne, tout en redessinant les marges imaginées de la nation. Ainsi, par le récit fantastique, Freitas esquisse les contours d'un roman qui peut être lu comme récit fantastique ou bien comme ficton politique.

PALAVRAS-CHAVE: romance gótico, Emília Freitas, literatura brasileira

\begin{abstract}
Quem seria aquela mulher? - pensava ele. Donde vinha? Para onde ia? Seria o anjo da saudade, perdido nas solidões da noite? As melancólicas notas daquele canto traduziriam o poema de um amor infinito sepultado nas cinzas do coração?

Por que capricho aquela criatura formosa, romântica e ideal misturava o belo com o horrível? Por que se acompanhava com figuras tão irrisórias?
\end{abstract}

(FREITAS, 1980, p.23)

Anselmo Peres Alós é doutorando em Letras pelo Programa de Pós-Graduação em Letras da UFRGS. 


\section{INTRODUÇÃO: PATRIARCADO, CÂNONE \& RESISTÊNCIA}

Em um primeiro momento, pode causar estranhamento conjugar os estudos sobre a literatura fantástica com uma política identitária estratégica como o feminismo. O que me motiva a pensar o fantástico e o gótico a partir de uma visada feminista é, antes de tudo, a circulação de um conhecimento informal no âmbito acadêmico em relação à autoria feminina no século XIX, permeado por clichês que desenham os romances de autoria feminina - a partir de um julgamento de valor precipitado, sem critérios formais efetivos de avaliação estética - como obras de pouca relevância estética. Faz-se assim necessário um conjunto de reflexões críticas a partir da perspectiva do outro, dos silenciados e excluídos por ocasião da organização e estabilização de um cânone, sobre a construção de uma identidade literária brasileira. Este processo de constituição de uma identidade literária associa a representação de uma identidade nacional a uma homogeneidade excludente, garantida a partir da diferenciação das esferas cultural e política. Na verdade, tais esferas são indissociáveis, como já demonstrou Edward Said em seu livro Cultura e Imperialismo (SAID, 1990, p.33-98). Propõe-se então o deslizamento do locus interpretativo do centro para as margens, criando-se assim um espaço de reflexão e análise que permita um novo olhar sobre obras lançadas ao esquecimento por parte da crítica literária. Para tanto, efetiva-se pois uma leitura ex-cêntrica e "marginal" deste romance, partindo-se do pressuposto de que as margens propiciam uma releitura e uma desestabilização do centro hegemônico responsável pelo estabelecimento dos valores literários normalmente considerados como modelares.

Uma reflexão sobre a produção das escritoras brasileiras do século XIX é tanto pertinente quanto necessária, na medida em que a exclusão da autoria feminina da historiografia literária se superpõe ao momento no qual o desenvolvimento de uma literatura brasileira está atrelado a um projeto de construção política de uma identidade nacional. A negação da legitimidade autoral aos textos escritos por mulheres denuncia, desta forma, a exclusão da participação feminina na produção desta identidade cultural brasileira. Em seu livro Teoria da Literatura, Terry Eagleton afirma que

(...) não existe uma obra ou uma tradição literária que seja valiosa em si, a despeito do que se tenha dito ou se venha a dizer sobre isso. Valor é um termo transitivo; significa tudo aquilo que é considerado valioso para certas pessoas em situações específicas, de acordo com critérios específicos e àluz de determinados objetivos (EAGLETON, 1983, p.12) .

Frente a esse argumento, afirmações típicas como a de que as obras escritas por mulheres não possuem valor literário se comparadas às dos 
autores canônicos perdem completamente sua validade. Ora, se valor é algo transitivo, definido a partir de momentos históricos específicos e com objetivos também específicos, cabe questionar quais foram os critérios mobilizados para a exclusão das escritoras do século XIX de nosso patrimônio literário. A principal dessas questões, como se verá adiante, diz respeito ao olhar que tais escritoras lançam sobre o projeto de construção de uma nacionalidade brasileira, pois sua condição de subordinação ao status quo patriarcal permitiu a elas uma visada crítica sobre a representação não só das mulheres, mas também de outros grupos minoritários no referido processo. Patriarcado e etnocentrismo estão conjugados sob a égide da dominação hegemônica, uma herança colonial que se faz presente até hoje na definição de quais obras são ou não são legítimas e representativas para a constituição do cânone literário brasileiro.

Salvo melhor juízo, nos manuais de História da Literatura Brasileira, o único escritor brasileiro que se aproxima da estética gótica durante o século XIX, tão em voga na Europa do século XVIII, foi Álvares de Azevedo. Talvez Augusto dos Anjos, com seu livro de poemas Eu (1912), mantenha também um certo parentesco com as convenções da literatura gótica. Entretanto, tendo em vista que nossa análise deita-se sobre o gênero narrativo (em especial o romance) e não sobre a lírica, não cabe aqui elencar ao lado de Álvares de Azevedo o poeta Augusto dos Anjos. Logo, à exceção dos contos de Noite na Taverna e do drama Macário (ambos de 1855), não se identifica no século XIX nenhum outro escritor brasileiro diretamente ligado a esse gênero setecentista de romance.

É neste ponto que fica justificado o resgate mencionado no título. Emília Freitas é uma romancista cearense que não apenas filiou sua escrita à do romance gótico, como também o "aclimatou", (tingindo-o com as cores tropicais) e o politizou, na medida em que usa estratégias narrativas e de construção de enredo - bem como de símbolos recorrentes nas narrativas góticas - para denunciar a opressão branca e patriarcal no século XIX de nosso país. Infelizmente, Emília Freitas foi também uma das vítimas silenciadas pela opressão contra a qual lutavam suas personagens, sendo apagada dos compêndios e histórias literárias.

\section{RESGATANDO EMÍLIA FREITAS DO ESQUECIMENTO}

A Rainha do Ignoto $^{1}$ foi publicado pela primeira vez em 1899. Esqueci-

${ }^{1}$ FREITAS, Emília. A Rainha do Ignoto: Romance Psicológico. 2. ed. Fortaleza: Secretaria Cultural do Desporto; Imprensa Oficial do Ceará, 1980. 
da pela crítica, a obra veio a ter uma segunda edição somente em 1980. Esta segunda edição conta com a atualização, revisão do texto e notas, apresentando também uma apresentação crítica realizada pelo Professor Otacílio Colares. A fortuna crítica da escritora, por sua vez, conta com uns poucos textos, a saber: um outro texto de Otacílio Colares, incluído no volume intitulado Lembrados e Esquecidos III ${ }^{2}$, de 1977, e o verbete sobre a escritora, de autoria de Constância Lima Duarte, publicado em Escritoras Brasileiras do Século XIX ${ }^{3}$, de 2000, volume organizado por Zahidé Lupinacci Muzart.

A narrativa situa-se temporal e espacialmente em uma pequena cidade cearense, às voltas da Gruta do Areré, lugar cujo folclore cearense diz habitado por fadas e espíritos, em um século XIX anterior à abolição da escravatura, tal como pode ser observado através do enredo da obra. Esta, por sua vez, "divide-se" em dois momentos distintos: um primeiro, no qual o cenário é a já referida cidadezinha cearense, e um segundo, no qual o palco da ação passa a ser o reino subterrâneo do Ignoto (e suas respectivas ligações com diversas partes da costa brasileira), lugar onde habitam a Rainha do Ignoto e suas paladinas, sempre prontas para defender os fracos das injustiças.

O romance conta a história do encontro de Edmundo (jovem advogado) com a Funesta, figura obscura que aparece por vezes à noite, e da qual dizem possuir pactos com fadas e demônios. A Funesta, entretanto, é apenas um dos inúmeros disfarces da Rainha do Ignoto, que se utiliza de variadas formas de encantamento, tais como o hipnotismo e o espiritismo kardecista, no intuito de realizar as tarefas às quais se propôs: guerrear a injustiça, proteger os fracos dos infortúnios, curar enfermos, salvar náufragos e vítimas de incêndios. Guiando suas paladinas e habitando um mundo obscuro e subterrâneo, a Rainha do Ignoto segue sua luta em defesa dos desfavorecidos.

Ajudado por Probo, personagem que representa a voz patriarcal hegemônica dentro da diegese romanesca, o jovem Edmundo penetra nos interstícios do reino do Ignoto. Probo, casado com uma mulher que recebeu a ajuda da Rainha do Ignoto, introduz o advogado recém-formado neste reino, acreditando que ele vai ajuda-lo a desmascarar a Rainha, uma anarquista que consegue, nas palavras de Probo, ser, ao mesmo tempo, abolicionista, republicana e espírita kardecista:

${ }^{2}$ COLARES, Otacílio. Lembrados e Esquecidos III. Fortaleza: Imprensa Universitária do Ceará, 1977.

${ }^{3}$ DUARTE, Constância Lima. "Emília Freitas". In: MUZART, Zahidé Lupinacci (org.) Escritoras Brasileiras do Século XIX. 2. ed. Florianópolis: Mulheres, 2000. 
- Tem idéias alevantadas e sãs - disse o Dr. Edmundo.

- Que sãs?! - exclamou Probo exaltado - veja, examine o que ela [a rainha do Ignoto] teme a petulância de declarar em um discurso que fez, na última sessão do Nevoeiro ${ }^{4}$ : "a pena última é o recurso dos governos impotentes para regenerar o criminoso pela instrução e pelo trabalho".

- Bem pensado!, senhor Probo.

- Bem pensado também incutir no âmbito dos que a rodeiam que o rei é o produto da ignorância dos povos antigos, que ainda não estavam em estado de se governarem e formar uma República.

- Bravo! Uma rainha republicana!

- Como Robespierre! Ou como Danton - acrescentou Probo.

- E o senhor quer-lhe mal por isso?

- Não é só por isso, senhor Edmundo, é por muitas outras idéias subversivas... Para não lhe faltar mais nadado que sublevar, é espírita! - Espírita! Mais este crime! - disse o Dr. Edmundo zombando. - O senhor zomba porque não conhece os males que ela causa às mais santas instituições, como sejam: ao direito de propriedade dos senhores, à monarquia e à religião (FREITAS, 1980, p.165-6).

Tal afronta à cultura hegemônica brasileira do final do século XIX (a saber: escravagista, monárquica e católica), ao mesmo tempo em que desperta a ira de Probo, atrai a simpatia de Edmundo, que aos poucos abandona a paixão sensual que cultivava pela Rainha. No lugar dessa paixão, surge uma imensa empatia, na medida que Edmundo compartilha dos ideais liberais da Rainha do Ignoto. Entretanto, como era de se esperar, o romance não foge ao script narrativo da época, e a heroína paga sua afronta à sociedade patriarcal duplamente: a Rainha não apenas fecha seu coração ao amor (mostrando assim a impossibilidade de conciliação entre a realização sentimental - esfera privada - e a realização social e política - esfera pública), mas também termina dando cabo à sua própria vida, suicidando-se no final do romance. Não bastando o suicídio da carne, a Rainha do Ignoto repete novamente a autodestruição quando invocada pela última vez pelas Paladinas, vencendo a morte através de um ato de denegação (dupla negação com finalidade eufemizante):

[Uma das paladinas:] - Qual foi a vossa missão na terra?

[Rainha do Ignoto:] - Não sei, nem vim para dizer-vos isto. Avaliai por vós mesmas os meus atos, classificai-os e deixai-me em paz; sofri muito na Terra, não gosto de voltar a ela.

${ }^{4}$ Nome dado às reuniões secretas que a rainha do Ignoto tinha com suas paladinas nos subterrâneos. 
ALÓS, Anselmo Peres

- Explicai-nos ao menos o mistério da Ilha do Nevoeiro, pediu Marciana.

- O daquela ilha onde viram tantas maravilhas, onde ficou o Palácio do Ignoto?

- Sim.

- Vou dizer-vos: ela foi possessão de todos os espíritos que encarnaram e me precederam na ordem genealógica da família. Ela foi passando de meus avós e deles a meus pais, que me conferiram o governo dela, ainda no período de minha existência terrena. Eles me auxiliavam no meio de ocultá-la dos olhos humanos e me davam força e sabedoria para governar o meio reino onde só se cuidava da elevação do caráter e do bem do próximo, esse onde a virtude achava refúgio e ante o qual a verdade não recuava com medo de ser batida como uma vil inimiga. Mas, ah! A Ilha do nevoeiro vai desaparecer por um fenômeno natural. Ninguém o verá. É noite, não há navio por estes mares; afastai os vossos destes lugares, se não quereis ser sepultada no fundo do oceano.

- O espírito da Rainha do Ignoto desapareceu com a flama azulada que tinha aparecido ali. Os navios se afastavam com rapidez. Já à distância suficiente para salvarem-se, ouviram as Paladinas um estrondo horrível.

- Uma enorme coluna de fumo aberta em forma de leque elevou-se às nuvens. Depois, línguas de fogo vermelho iam crescendo em lençóis de chamas movediças, que dançavam no espaço.

- As águas daquele mar ficaram em ebulição, cresceram até formar uma enorme montanha que subiu e desceu repentinamente, para engolir tudo que lhe ficava ao alcance.

A Ilha do Nevoeiro era de origem vulcânica; desapareceu no seio do oceano, com a Rainha do Ignoto no meio do Infinito (FREITAS, 1980, p.358-9).

Remontemo-nos a Emile Durkheim e as idéias por ele desenvolvidas em Le Suicide (1897). Nesta obra, Durkheim define três tipos de suicídio: o suicídio egoísta, o suicídio altruísta e o suicídio anômalo. O primeiro deles (egoísta) é o resultado de uma individualização exagerada do sujeito social frente ao coletivo no qual está inserido. De acordo com Durkheim, "[q] uanto mais enfraquecidos sejam os grupos a que [o sujeito] pertence, menos depende deles e mais (...) depende apenas de si próprio por não reconhecer outras regras de conduta que as estabelecidas no seu interesse privado" (DURKHEIM, , 1981, 109). Logo, esse tipo de suicídio é o resultado de uma afirmação desmesurada do ego individual frente ao ego social. O segundo tipo, o altruísta, resulta quando a decisão do suicídio é tomada tendo-se em mente que ele, mais do que necessário, é uma obrigação do sujei- 
to social para com o coletivo. Ele acontece, por exemplo, no caso de homens que estão no auge da velhice, ou de mulheres que se sentem obrigadas a dar cabo à própria existência por ocasião da morte do marido. Quando não se configura como prescrição social, pode se configurar como prescrição religiosa (como quando, por exemplo, é preferível o suicídio aos castigos morais ou sobrenaturais, em certas culturas primitivas). $\mathrm{O}$ suicídio anômalo, por sua vez, acontece quando a ação de autodestruição é movida por não se ter mais perspectivas futuras, como se não houvesse mais como evoluir socialmente. A partir do momento em que o sujeito atinge uma certa posição de poder que lhe permita não se submeter às regras ditadas pelo social, ele não vê mais motivos para existir socialmente. Tal como o suicídio egoísta, ele também decorre de uma hipertrofia do ego individual frente ao ego social, mas ambos são movidos por razões distintas.

A idéia de autodestruição pode materializar-se de diferentes maneiras nos textos góticos. Na obra Frankenstein, de Mary Shelley por exemplo, a autodestruição não se dá pelo suicídio, mas sim pelo autoexílio ao qual a fantástica criatura se submete, abandonando o mundo e escondendo-se no Pólo Norte. Emília Freitas, entretanto, lança mão de um duplo suicídio para a Rainha do Ignoto. Se tomarmos como referência apenas a primeira morte - a física -, poderíamos afirmar que o suicídio da Rainha se enquadraria na terceira das categorias descritas por Durkheim. Ou seja, dado o alcance ao qual a protagonista chega - interferindo em um mundo falo e etnocêntrico - poderia alcançar o estado de anomia social, o que a levaria ao suicídio. Entretanto, a partir do momento em que a segunda morte da protagonista (seguida pela erupção vulcânica que leva a Ilha do Nevoeiro para o fundo do oceano) entra em cena, fica claro que a estrutura do seu suicídio é egoísta: tal é a individualização do ego da Rainha do Ignoto que se torna impossível a conciliação com o ego social. Nesse contexto não apenas o adjetivo "egoísta", mas a própria noção "suicídio" deve ser revistas para que melhor se possa compreender o destino da protagonista.

O suicídio não deve ser aqui visto de uma forma derrotista, uma alegoria do fracasso feminino na esfera pública de atuação política. Se o patriarcado tem o poder de definir as limitações da participação de uma mulher na sociedade (ou ela cumpre o seu papel de mãe e esposa, atendendo às demandas socialmente construídas, ou então ela age "subterraneamente" - e aqui o reino subterrâneo do Ignoto presta-se a cumprir a função de alegoria das condições de atuação da mulher na época - pois, para interferir nas configurações político-culturais, as mulheres em geral têm - tal como a Rainha do Ignoto - de camuflar suas ações), o suicídio mostra-se como ato máximo de emancipação, na medida em que o sujeito feminino exerce o seu último poder: o de optar pela não-existência nesse conturbado contexto social. 
ALÓS, Anselmo Peres

Para Gilbert Durand, em As Estruturas Antropológicas do Imaginário ${ }^{5}$, a idéia de um mundo subterrâneo está intimamente ligada ao que ele chama de dominante digestiva da imagem, na qual imperam as estruturas místicas e antifrásticas. Através da operacionalização da denegação, uma dupla negação de caráter eufemístico, o binarismo essencialista céu-alturas-redenção e inferno-profundezas-perdição é relativizado, e o dualismo do Bem versus o Mal é deslocado. Assim, o Reino do Ignoto, enquanto reino subterrâneo, não emerge no romance de Freitas como alguma espécie de Hades helênico ou Inferno cristão. Ao contrário, aponta para uma energia contida e recalcada no mundo "da superfície" (a realidade patriarcal, monárquica e escravagista do Brasil oitocentista descrito pela escritora) que, no entanto, reaparecem em um outro lugar (o Reino do Ignoto, no qual são defendidos os ideais de igualdade entre homens e mulheres, a abolição do regime escravocrata e de um governo republicano), interferindo na sucessão de acontecimentos desse mundo superficial. Assim a Rainha do Ignoto, que na superfície é vista como "A Funesta", uma fada maligna, no Reino do Ignoto é mostrada como uma mulher que não aceita ser reduzida à condição de objeto da história: ela é transformada em agente histórico e social do seu tempo.

Se para o leitor desavisado possa parecer um oxímoro criado pela autora o fato de uma personagem com o título de "Rainha" defender ideais abolicionistas e (principalmente) republicanos, cabe ressaltar que a figura da "Rainha do Ignoto" não é nada mais do que, como mencionado anteriormente, um dos disfarces utilizados pela protagonista, chamada Diana, para poder lutar contra as injustiças. O Reino do Ignoto, mais do que um império governado por um coletivo de mulheres de obscuros poderes sobrenaturais, é a cristalização de uma utopia não apenas sonhada pelas mulheres, mas por todos os oprimidos de todos os tempos e de todas as nações. $O$ fato de ser uma monarquia governada por uma mulher kardecista, na qual outras mulheres, crianças enjeitadas, negros fugidos e trabalhadores são acolhidos não torna o Reino do Ignoto uma nação antagonizante com a cidadezinha cearense - e, por metonímia, com toda a nação brasileira -, mas ao contrário, retrata e cristaliza em uma obra literária aquilo que o crítico indo-britânico Homi K. Bhabha chama de "as fronteiras internas

${ }^{5}$ Trad. Hélder Godinho. São Paulo: Martins Fontes, 1997. Não cabe nos determos aqui em uma longa explanação sobre o trabalho de Durand. Lançamos mão de sua obra na medida em que seu pensamento é de grande monta para evidenciar significados simbólicos da obra sem, no entanto, aprofundarmo-nos em suas reflexões sobre a mitocrítica e a mitoanálise. 
da nação" em seu artigo "DissemiNação: O Tempo, A Narrativa e As Margens da Nação Moderna” (BHABHA, 1998, p.198-238).

\section{RASTREANDO AS FILIAÇÕES GÓTICAS}

O romance foi descrito, nos parcos estudos sobre ele existentes, como um texto que mistura, em sua composição, elementos do regionalismo e do ultra-romantismo, deslizando a partir do segundo momento da narrativa para os domínios do fantástico, e incorporando à obra elementos sobrenaturais. Otacílio Colares, em seu estudo publicado juntamente com a segunda edição da obra, afirma o seguinte:

Romances como A Rainha do Ignoto, de Emília Freitas (1899) e A Divociada, de Francisca Clotilde (1902) desbordaram, por retardos, dos parâmetros naturalistas da sua contemporaneidade, apresentando-se o segundo com a simpleza do costumismo regional nordestino e o primeiro com os apelos ao imponderável, por facilidade de algum acoimado de espírita, quando mais não foi, nas intenções de sua autora, que uma fuga propositada ao passado, ao que se convencionou denominar romance gótico, embora partindo do regional mais autêntico.

(...)

Não seria talvez ousio demasiado pensar-se em ligar certos passos fantásticos (por serem demais fantasiosos) de A Rainha do Ignoto, de Emília Freitas, até mesmo à influência de cantorias certamente ouvidas por ela, em menina, dos cantadores, cearenses ou de outras províncias, os quais, por força, ao longo do passado século, teriam varejado o Ceará, tendo por ponte natural a então próspera região do vasto Aracati, onde o pai da futura romancista era senhor de quase um feudo, nas de entre as hoje cidades Jaguaruana e Itaiçaba, dantes, respectivamente, União e Passagem das Pedras (COLARES, 1980, p.10-11).

No rastreamento das afiliações de $A$ Rainha do Ignoto ao gênero romanesco, identifica-se na obra, tal como já havia constatado Otacílio Colares por ocasião da reedição da obra de Freitas, a presença de elementos do romance gótico, vertente européia do romance setecentista vista por grande parte da crítica literária do século XX como o "esqueleto no armário" da tradição romântica européia (WILLIAMS, 1995, p.1). O gótico começa a despertar interesse acadêmico apenas no final do século XX.

Em uma perspectiva romântica (entendendo-se aqui "romântico" na 
acepção de romantismo europeu do século XIX), o gótico não é tanto um esqueleto no armário, mas a "ovelha negra" da família romântica, situado às margens da tradição literária da época. Por ter sido considerado durante muito tempo como um gênero popular menos, destinado ao consumo massificado, os estudiosos que se dedicam ao estudo dos grandes poetas não costumam considerar filiações a temas góticos encontrados nos mesmos, tais como as que se evidenciam em poetas como William Blake e Samuel Coleridge. Vejamos o poema "The Sick Rose" (a Rosa Doente), de W, Blake, no qual é possível averiguar essa filiação:

The Sick Rose

O Rose, thou art sick.

The invisible worm,

That flies in the night

In the howling storm:

Has found out thy bed

Of crimson joy;

And his dark secret love

Does thy life destroy ${ }^{6}$.

(BLAKE, 1984, p.11)

Pode-se perceber neste poema traços típicos do gótico, como a inseparabilidade do amor e da morte, assim como um projeto estético frio e nebuloso, escuro, no qual a degradação é exaltada. A imobilidade da Rosa (cuja inicial maiúscula permite que se interprete a flor como um nome próprio, transformando-se metonicamente a rosa no sujeito feminino) condena-a à degradação, da mesma forma que as personagens em romances góticos estão, muitas vezes, acorrentadas a definharem por causa de sua natureza, tal como o monstro de Frankenstein. E, tal como ocorreu na literatura inglesa, Emília Freitas transformou-se em um epígono da literatura brasileira, por ser uma mulher escritora em tempo no qual a elas não era dada mais do que o cuidado da casa e dos filhos, e por praticar convenções literárias em sua escrita que não condiziam com o projeto estético de sua época.

Na composição do cenário gótico europeu, há invariavelmente a presença de elementos associados ao período medieval, sempre pensado como a Idade das Trevas. Desta forma, o tropos do castelo e seus labirintos (tão caro

6"Ó Rosa, estás doente./O inseto invisível?Que voa à noite/Na tempestade ruidosa:/Descobriu teu leito/de prazer carmim:/E seu sombrio amor secreto?Tua vida destrói". 
ao gótico) é traduzido no romance de Emília Freitas como a Gruta do Areré, dado ser esta imagem mais legítima dentro de um projeto de literatura nacional - tendo-se em mente o a ambiente oitocentista das letras brasileiras, no qual a cor local passa a ser um signo de nacionalidade. O labirinto, por sua vez - que nas narrativas góticas européias estava cristalizado nas formas obscuras e truncadas dos corredores e masmorras do castelo medieval - surge na obra de Emília Freitas como um imbricado reino subterrâneo, dada a inexistência de castelos sombrios em nosso cenário tropical.

Dentre os procedimentos formais do romance gótico utilizados pela autora, merece destaque a estratégia narrativa. Sendo um dos pontos altos do romance gótico a tensão e a expectativa, de forma a prender a atenção do leitor, a metalepse figura como um importante recurso formal. A metalepse é uma estratégia narrativa com forte potencial para a criação de tensão, pois no momento em que há o desvio para um plano metadiegético (a inserção de uma outra narrativa dentro da narrativa), há a suspensão temporária no âmbito dos acontecimentos da narrativa primeira. Importante não confundir, pois, a metalepse com o mise-en-abîme, um tipo específico de metalepse. Enquanto a metalepse dá conta da inserção de um outro nível diegético seja qual for o meio de inserção desse nível, o mise-enabîme dá conta de um tipo particular de ruptura no nível diegético (a saber: aquele no qual uma segunda narrativa, aparentemente sem nenhuma ligação com os eventos da narrativa primeira, é inserida nessa de forma a esclarecer metaforicamente outros pontos da trama). Um exemplo disso é a história "Amor e Psiquê" inserida em O Asno de Ouro, de Apuleio.

Uma das metalepses mais importantes em A Rainha do Ignoto ocorre no capítulo intitulado "Um caso dos que vão pelo mundo: continua a narração do caçador de onças " "FREITAS, 1980, p.131). O caçador de onças é Probo, um dos poucos homens que conhece as atividades das paladinas. Assim, a narrativa principal é estancada, e o narrador - heterodiegético intruso - cede a Probo, momentaneamente, o seu espaço, abrindo um outro nível narrativo, metadiegético, que gera tensão e expectativa justamente por paralizar a ação principal: a entrada de Edmundo nos interstícios do Reino do Ignoto.

O Dr. Edmundo pensou, toda noite, no que ouvira contar o caçador de onças; não podia acreditar em tudo aquilo, porque lhe pareceu exage-

\footnotetext{
${ }^{7}$ Ainda que a história que o caçador de onças conta a Edmundo comece no capítulo anterior, é apenas neste que a metalepse emerge como recurso estilístico característico da escritura gótica. No capítulo anterior, este outro nível diegético é inserido através de um diálogo entre o caçador e Edmundo, e não através de uma ruptura metaléptica no fio da narrativa.
} 
ALÓS, Anselmo Peres

rado; mas, abstraindo o verossímil do inverossímil, achou que ainda ficavam coisas muito interessantes e dignas de serem estudadas.

(...)

No dia seguinte, às mesmas horas, estava no lugar aprazado, esperando o caçador de onças. Este não tardou muito a aparecer, levouo para a cabana, e continuou a narrativa interrompida:

- A princípio, disse Probo, eu zombava de Roberta, chamava-lhe visionária, dizia que ela estava com o espírito imbuído de magias; mas uma noite ela me disse:

- Observa, Probo, e depois julga. Hoje vai haver sessão, estamos num porto. Disse-me a Brasília [outro codinome da Rainha do Ignoto] que vem entrar para o Ignoto mais uma Paladina. Se queres assistir à bruxaria, como tu chamas, anda comigo a um lugar de onde poderemos ver sem ser vistos.

- Acompanhei a Roberta, nos escondemos, e vimos o que se passava no salão de ré, naquela hora de defeso para nós. Ali estava a Rainha do Ignoto, muito pequena e muito franzina; mas de porte airoso e gostos soberbos! Trajava vestido de veludo preto, e tinha um diadema cravejado de brilhantes; mas, estava como sempre, mascarada (FREITAS, 1980, p.131-2).

O narrador do romance apenas inicia o capítulo, cedendo espaço para que o personagem Probo conte o que viu quando esteve no reino do Ignoto. É interessante notar que, embora o narrador dê total liberdade narrativa para o personagem, Freitas opta pelo discurso direto, marcado por travessões, ao invés de utilizar o discurso indireto. Tal opção permite que mesmo Probo, personagem que detém durante este capítulo a instância narrativa, inclua a perspectiva de Edmundo e Roberta (esposa de Probo, que ao contrário do marido, simpatiza com a Rainha do Ignoto e com seus ideais), como é possível observar no quarto parágrafo da citação anterior. Assim, a partir da descrição da cena da sessão espírita e da cerimônia de inclusão de uma nova paladina no Ignoto, é possível identificar as reações de cada personagem aos ideais e às práticas da Rainha: Edmundo mostrase (neste momento) interessado, mais muito mais curioso do que partidário, enquanto Probo opõe-se totalmente e Roberta identifica-se.

Pode-se considerar o romance gótico não apenas como uma resposta ao romance realista setecentista, mas também como uma resposta ao racionalismo iluminista. Se a sociedade é vista como aquilo que corrompe o homem (como, por exemplo, na obra de Rousseau), e a natureza é tornada o lugar ideal e sem corrupção (a bondade inata do bon sauvage, tão aclamado pelo momento indianista da nossa literatura romântica), o gótico vai responder a essas idéias mostrando a natureza como mãe terrível, lócus privilegiado do dionisíaco, do irracional e do inconsciente, das forças 
desgovernadas e imprevisíveis, da lei do forte, enfim.

O gosto pelo gótico, investido de três significados contíguos (o bárbaro, o medieval e o sobrenatural) foi um dos elementos formadores do Romantismo, e não um galho definhado na árvore genealógica dos gêneros romanescos. Estes três significados podem ser identificados em A Rainha do Ignoto de forma surpreendentemente clara. Entretanto, para que se possa identificalos, é necessário ter em mente que as convenções do gótico não são completa e integralmente transplantadas para o contexto fin-de-siècle brasileiro. Ao utilizar elementos góticos em seu romance, Freitas o faz colocando-os em funcionamento dentro de um projeto narrativo no qual a questão política da luta contra a opressão e a injustiça se constitui enquanto questão-chave da visão utópica projetada pela narrativa. Ou seja: uma sociedade reformulada a partir de uma práxis pautada no poder de ação de uma militância organizada por mulheres emancipadas. Tal sociedade, entretanto, não se cristaliza sob a bandeira da misoginia: ao contrário, homens trabalhadores e negros são incluídos no seio da sociedade como cidadãos legítimos, a partir da ajuda das Paladinas, enquanto o poder opressor da sociedade oitocentista (imperial, patriarcal e escravocrata) é questionado pela prática feminista avant la lettre das companheiras da Rainha do Ignoto.

Avançar no conhecimento que se tem sobre o passado significa redimensionar, no presente, os nossos conceitos de literatura e cultura, para projetar uma visão de cultura dialógica e plural que, efetivamente, expresse o choque dos valores e encene a diferença como marca de mobilidade permanente do coletivo e das identidades sociais, culturais, nacionais e literárias.

\section{BIBLIOGRAFIA}

ANJOS, Augusto dos. Eu e Outras Poesias. Porto Alegre: L\&PM, 1999.

APULEIO. O Asno de Ouro. Rio de Janeiro: Ediouro, [s.d.]

AZEVEDO, Álvares de. Noite na Taverna. Rio de Janeiro: Ediouro, [s.d.] . Macário. [s.d.t.] (Fotocópia).

BHABHA, Homi K. O Local da Cultura. Trad. Myriam Ávila, Eliana Lourenço de Lima Reis e Gláucia Renate Gonçalves. Belo Horizonte; UFMG, 1998.7

. DissemiNação: O Tempo, A Narrativa e As Margens da Nação Moderna. In: ___ O Local da Cultura. Trad. Myriam Âvila, Eliana Lourenço de Lima Reis e Gláucia Renate Gonçalves. Belo Horizonte; UFMG, 1998. p.198-238). 
ALÓS, Anselmo Peres

BLAKE, William. Songs of Experience. New York: Dover Publications, 1984. Facsimile Reproduction with 26 Plates in Full Color. p.33.

COLARES, Otacílio. Lembrados e Esquecidos III. Fortaleza: Imprensa Universitária do Ceará, 1977.

DUARTE, Constância Lima. Emília Freitas. In: MUZART, Zahidé Lupinacci (org.) Escritoras Brasileiras do Século XIX. 2. ed. Florianópolis: Mulheres, 2000.

DURAND, Gilbert. As Estruturas Antropológicas do Imaginário. Trad. Hélder Godinho. São Paulo: Martins Fontes, 1997.

DURKHEIM, Émile. Textos Escolhidos. 2. ed. Org. José Albertino Rodrigues. São Paulo: Ática, 1981.

FREITAS, Emília. A Rainha do Ignoto: Romance Psicológico. 2. ed. Fortaleza: Secretaria Cultural do Desporto; Imprensa Oficial do Ceará, 1980.

EAGLETON, Terry. Marxism and Literary Theory. Berkeley; Los Angeles: University of California Press, 1976.

Teoria da Literatura: Uma Introdução. Trad. Waltersin Dutra. São Paulo: Martins Fontes, 1983.

SAID, Edward. Cultura e Imperialismo. Trad. Denise Botmann. São Paulo: Companhia das Letras, 1990.

SHELLEY, Mary. Frankenstein. Trad. Miécio Araújo Jorge Honkins. Porto Alegre: L\&PM, 1999.

WILLIAMS, A. Art of Darkness: tho poetics of gothic. London: Blackwell, 1995.

MUZART, Zahidé Lupinacci (org.) Escritoras Brasileiras do Século XIX. 2. ed. Florianópolis: Mulheres, 2000. 